\title{
A1 Adenosine Receptor Upregulation and Activation Attenuates Neuroinflammation and Demyelination in a Model of Multiple Sclerosis
}

\author{
Shigeki Tsutsui, ${ }^{1}$ Jurgen Schnermann, ${ }^{3}$ Farshid Noorbakhsh, ${ }^{1}$ Scot Henry, ${ }^{1}$ V. Wee Yong, ${ }^{1}$ Brent W. Winston, ${ }^{2}$ \\ Kenneth Warren, ${ }^{4}$ and Christopher Power ${ }^{1}$ \\ Departments of ${ }^{1}$ Clinical Neurosciences and ${ }^{2}$ Critical Care Medicine, University of Calgary, Calgary, Alberta T2N 4N1, Canada, ${ }^{3} \mathrm{National}$ Institute of \\ Diabetes and Digestive and Kidney Diseases, National Institutes of Health, Bethesda, Maryland 20892-1370, and ${ }^{4}$ Department of Medicine, University of \\ Alberta, Edmonton, Alberta T6G 2B7, Canada
}

The neuromodulator adenosine regulates immune activation and neuronal survival through specific G-protein-coupled receptors expressed on macrophages and neurons, including the A1 adenosine receptor (A1AR). Here we show that A1AR null (A1AR ${ }^{-l-}$ ) mice developed a severe progressive-relapsing form of experimental allergic encephalomyelitis (EAE) compared with their wild-type $\left(\mathrm{AlAR}^{+/+}\right)$littermates. Worsened demyelination, axonal injury, and enhanced activation of microglia/macrophages were observed in $\mathrm{A}_{\mathrm{AR}}{ }^{-1-}$ animals. In addition, spinal cords from $\mathrm{AlAR}^{-1-}$ mice demonstrated increased proinflammatory gene expression during EAE, whereas anti-inflammatory genes were suppressed compared with $\mathrm{AlAR}^{+/+}$animals. Macrophages from A1AR ${ }^{-1-}$ animals exhibited increased expression of the proinflammatory genes, interleukin- $1 \beta$, and matrix metalloproteinase-12 on immune activation when matched with $\mathrm{A}_{1} \mathrm{AR}^{+/+}$control cells. A1 $\mathrm{AR}^{-/-}$macrophage-derived soluble factors caused significant oligodendrocyte cytotoxicity compared with wild-type controls. The A1AR was downregulated in microglia in $\mathrm{AlAR}^{+/+}$mice during EAE accompanied by neuroinflammation, which recapitulated findings in multiple sclerosis (MS) patients. Caffeine treatment augmented A1AR expression on microglia, with ensuing reduction of EAE severity, which was further enhanced by concomitant treatment with the A1AR agonist, adenosine amine congener. Thus, modulation of neuroinflammation by the A1AR represents a novel mechanism that provides new therapeutic opportunities for MS and other demyelinating diseases.

Key words: EAE; cytokines; MMPs; demyelination; adenosine amine congener; caffeine

\section{Introduction}

The endogenous purine nucleoside adenosine regulates a variety of physiological processes, including neuronal survival (Ribeiro et al., 2002) and suppression of inflammation (Cronstein, 1994). The biological effects of adenosine are mediated by four different subtypes of G-protein-coupled cell surface receptors (A1, A2a, $\mathrm{A} 2 \mathrm{~b}$, and $\mathrm{A} 3$ ), all of which have been shown to regulate the synthesis and release of immunomodulatory molecules, including cytokines, matrix metalloproteinases (MMPs), and reactive oxygen species (Boyle et al., 1996; Hasko et al., 1996). In recent studies, the activation of adenosine receptors on immune cells suppressed the production of proinflammatory mediators, in-

Received Sept. 18, 2003; revised Dec. 15, 2003; accepted Dec. 15, 2003.

S.T. is a Multiple Sclerosis Society of Canada (MSSC) Fellow, V.W.Y. is an Alberta Heritage Foundation for Medical Research (AHFMR) Senior Scholar/Canadian Institutes of Health Research (CIHR) Scientist, B.W.W. is an AHFMR Clinical Investigator, and C.P. is an AHFMR Scholar/CIHR Investigator. These studies were supported by the MSSC and CIHR-Interdisciplinary Health Research Team. We thank Ken Jacobson and Dominic Corkill for helpful discussions; Andrea Sullivan, Connie Mowat, and Claudia Silva for technical assistance; and Belinda Ibrahim for manuscript preparation.

Correspondence should be addressed to Dr. Christopher Power, Neuroscience Research Group, Department of Clinical Neurosciences, University of Calgary, Heritage Medical Research Building, Room 150, 3330 Hospital Drive Northwest, Calgary, AB T2N 4N1, Canada. E-mail: power@ucalgary.ca.

DOI:10.1523/JNEUROSCI.4271-03.2004

Copyright $\odot 2004$ Society for Neuroscience $\quad$ 0270-6474/04/241521-09\$15.00/0 cluding tumor necrosis factor (TNF)- $\alpha$ (Bouma et al., 1994; Hasko et al., 1996; Sajjadi et al., 1996) and MMPs (Boyle et al., 1996), while also increasing the expression of neuroprotective and anti-inflammatory cytokines, including interleukin-6 (IL-6) and IL-10 (Hasko et al., 1996; Le Moine et al., 1996; Schwaninger et al., 1997). Adenosine receptor agonists also appear to influence other macrophage properties, such as phagocytosis and chemotaxis, thereby reducing leukocyte accumulation at sites of inflammation (Cronstein, 1994; Olah and Stiles, 1995). In the CNS, the A1 adenosine receptor (A1AR) is highly expressed on microglia/ macrophages and neurons but not on infiltrating lymphocytes (Johnston et al., 2001a), although its effects on neuroinflammation remain uncertain.

Multiple sclerosis (MS) is a chronic debilitating disease of the CNS characterized by neuroinflammation, which results in ongoing demyelination and axonal/neuronal injury mirrored by progressive, usually relapsing, physical disability (Lassmann et al., 2001). Although the cause of MS remains unknown, acquired immunity, including $\mathrm{T}$ - and $\mathrm{B}$-cell responses targeting myelin proteins, determines the early stages of disease, whereas innate immune mechanisms with macrophage/microglia activation are pivotal in disease initiation and progression together with the selective expression and release of inflammatory mediators by 
activated immune cells, such as cytokines (Navikas and Link, 1996), chemokines (Bar-Or et al., 1999; Sorensen et al., 1999), and MMPs (Chandler et al., 1997; Yong et al., 1998). Several immunomodulatory agents inhibit the development of disease in an animal model of MS, experimental autoimmune encephalomyelitis (EAE) (Miller and Shevach, 1998; Neuhaus et al., 2003), and in some cases have been shown to influence the course of human disease (Neuhaus et al., 2003). Thus, regulating inflammatory mediators and reducing innate immune activation is a rational therapeutic strategy for MS.

Previous studies from our group have reported that A1AR expression and activity on macrophage/microglial cells were diminished in MS patients compared with controls with concurrent cytokine dysregulation (Mayne et al., 1999; Johnston et al., 2001a). Thus, we hypothesized that the A1AR controlled the extent of neuroinflammation and associated demyelination in MS and EAE. Here, we report that reduced A1AR expression results in a more severe progressive EAE phenotype, which is accompanied by innate neuroimmune activation with augmented myelin damage and axonal loss. Moreover, the severity of EAE was abrogated by concomitant treatment with the A1AR modulator caffeine and the A1AR agonist adenosine amine congener (ADAC).

\section{Materials and Methods}

Induction and treatment of EAE. Homozygous A1AR null mice $\left(\mathrm{A}_{1 \mathrm{AR}^{+/+}}\right)$and littermate wild-type $\left(\mathrm{A} 1 \mathrm{AR}^{-1-}\right)$ controls were generated as described previously (Sun et al., 2001). To induce EAE, agematched female mice were each injected subcutaneously with $50 \mu \mathrm{g}$ of myelin oligodendrocyte glycoprotein $\left(\mathrm{MOG}_{35-55}\right)$ (Brundula et al., 2002) emulsified in complete Freund's adjuvant (Difco Laboratories, Detroit, MI), together with $300 \mathrm{ng}$ of reconstituted lyophilized pertussis toxin (List Biological Laboratories, Campbell, CA). The pertussis toxin injection was repeated after $48 \mathrm{hr}$ (Liu et al., 1998). For caffeine- and ADAC-related experiments, EAE was induced in female 129/SvEv mice and treated by implanting subcutaneous osmotic Alzet pumps (Durect, Cupertino, CA) containing caffeine or ADAC or vehicle (saline or $1 \%$ DMSO) to maintain constant caffeine and ADAC concentrations. Caffeine treatment $(0.2-2.0 \mathrm{mg} / \mathrm{kg})$ was initiated at the time of MOG immunization and continued until the animals were killed. ADAC $(10 \mu \mathrm{g} / \mathrm{kg})$ was initiated at day 12 after MOG immunization. Animals were assessed daily for EAE severity for $60 \mathrm{~d}\left(\mathrm{AlAR}^{+/+}\right.$and $\mathrm{A} 1 \mathrm{AR}^{-/-}$animals) or for $25 \mathrm{~d}$ in the caffeine-, ADAC-, and vehicle-treated animals using a $0-5$ rating scale (Liu et al., 1998) as follows: 0 , no disease; 1 , limp tail; 2 , partial paralysis of one or two hindlimbs; 3 , complete paralysis of hindlimbs; 4 , hindlimb paralysis and forelimb paraparesis; 5 , moribund. The animals were killed by cardiac puncture and perfusion with PBS under methoxyflurane anesthesia; they were treated according to Center for Animal Care and Control guidelines, and this study was approved by the University of Calgary Animal Care Committee.

Histological analysis. The brain and spinal cord were removed from euthanized animals, immersed in $10 \%$ neutral buffered formalin, and embedded in paraffin wax as reported previously (Brundula et al., 2002). Four micrometer sections, taken from cervical and lumber spinal cord regions, were stained by Bielschowsky's silver impregnation. The axonal number was quantified by counting the silver-positive axonal fibers per square millimeter in $\mathrm{A}_{\mathrm{AR}}{ }^{+/+}$and $\mathrm{AlAR}^{-/-}$mice. Five randomly chosen fields in white matter from each spinal cord section were scanned with a Zeiss (Oberkochen, Germany) Axioskop 2 upright microscope and Spot system (Diagnostic Instruments, Sterling Heights, MI) to provide digital images. Quantitative analysis of axonal numbers per square millimeter was performed using Adobe Photoshop (San Jose, CA) and the public domain program Scion Image (Scion, Frederick, MD). Briefly, black axonal fibers in white-matter tracts were captured in Adobe Photoshop and axons per square millimeter were counted in Scion Image.

Immunohistochemistry. To detect macrophages/microglia, astrocytes, and neurons, antibodies to ionized calcium binding adaptor molecule 1 (Iba-1) (provided by Dr. Y. Imai; Imai et al., 1996), glial fibrillary acidic protein (GFAP) (Dako, Carpinteria, CA), and neuronal nuclei (NeuN) (Chemicon, Temecula, CA) (Iba-1, $1 \mu \mathrm{g} / \mathrm{ml}$; GFAP, 1:2000; NeuN, 1:100) were used, respectively, together with the Vectastain ABC-Elite kit (Vector Laboratories, Burlingame, CA) (Power et al., 2003). An examiner who was unaware of the slide identity performed cell counts of Iba-1- and GFAP-immunopositive cells in the white matter of spinal cords and NeuN-immunopositive cells in the frontal lobes of brains. Five randomly chosen fields in white-matter tracts from each spinal cord section were scanned as described above. The quantitative analysis of cell counts per square millimeter was performed using Adobe Photoshop and Scion Image (Scion Corporation) as described above.

Immunofluorescence and confocal laser scanning microscopy. Paraffinembedded sections were deparaffinized and preincubated with $10 \%$ normal goat serum, $2 \%$ BSA, and $0.2 \%$ Triton $\mathrm{X}-100$ overnight at $4^{\circ} \mathrm{C}$ to prevent nonspecific binding. Primary antibody mouse anti-myelin basic protein (MBP) (1:1000 dilution; Sternberger Monoclonals, Lutherville, MD) was diluted in 5\% normal goat serum, $2 \%$ BSA, and $0.2 \%$ Triton $\mathrm{X}-100$, and incubated overnight at $4^{\circ} \mathrm{C}$. After washing, the sections were incubated with $\mathrm{Cy}-3$ goat anti-mouse secondary antibody (1:500 dilution; Jackson ImmunoResearch, West Grove, PA) for $2 \mathrm{hr}$ at room temperature in the dark, and mounted with fluorescent mounting medium. Slides were examined on an Olympus (Tokyo, Japan) Fluoview (FV300) confocal laser scanning microscope. An examiner who was unaware of the slide identity calculated the percent vacuolar change in the white matter of spinal cords, and quantitative analysis was performed as described previously (Linker et al., 2002). Cultured oligodendrocytes (OLs) derived from adult rat brains were stained with an $\mathrm{O} 1$ monoclonal antibody that recognizes galactocerebroside (GalC), a marker for mature OLs (Sommer and Schachner, 1981; Bansal et al., 1989). Goat anti-mouse antibody conjugated to $\mathrm{Cy}-3$ (Jackson ImmunoResearch) was used as the secondary antibody to detect labeled OLs. Mouse OLs extend several thread-like processes from soma, which facilitated the counting of the percentage of O1-positive cells with processes (Oh et al., 1999). The number of cells exhibiting processes at $24 \mathrm{hr}$ was measured after treatment with the conditioned medium from bone marrow-derived macrophages (BMDM) from $\mathrm{A} 1 \mathrm{AR}^{+/+}$or $\mathrm{A} 1 \mathrm{AR}^{-/-}$. To confirm the identity of cells expressing A1AR, double staining was performed using Alexafluor-488-conjugated goat anti-rabbit secondary antibody (1:500 dilution; Molecular Probes, Eugene, OR) to detect the Iba-1 polyclonal antibody and $\mathrm{Cy}$-3-conjugated donkey anti-goat secondary antibody (1:500 dilution; Jackson ImmunoResearch) to detect the A1AR polyclonal antibody (1:200 dilution; Santa Cruz Biotechnology, Santa Cruz, CA). Deparaffinized sections were preincubated with $5 \%$ donkey and horse serum, $2.5 \%$ mouse serum, $2 \%$ BSA, and $0.2 \%$ Triton X-100 overnight at $4^{\circ} \mathrm{C}$ to prevent nonspecific binding. Antigen retrieval was achieved by the pretreatment of sections for $10 \mathrm{~min}$ in $10 \mathrm{~mm}$ sodium citrate buffer, $\mathrm{pH}$ 6.0 , in a microwave oven. The specificity of staining was confirmed by omitting the primary antibody. Slides were examined on an Olympus FV300 confocal laser scanning microscope.

Real-time reverse transcription PCR. Animals were killed by cardiac puncture under methoxyflurane anesthesia $60 \mathrm{~d}$ after the induction of EAE, and lumbar-sacral spinal cords were collected. Spinal cord tissue was dissected, homogenized, and then lysed in TRIzol (Invitrogen, Gaithersburg, MD), according to the manufacturer's guidelines. Total cellular RNA was isolated and dissolved in diethylpyrocarbonate-treated water, $1 \mu \mathrm{g}$ of RNA was used for the synthesis of complementary DNA, and PCRs were performed as described previously. All mouse primer sequences were established previously (Overbergh et al., 1999; Sun et al., 2001), except for A2aAR (5'-CGCCATCCCATTCGCCATCAC-3' and 5' -CCTTCGCCTTCATACCCGTCACCA-3'), A3AR (5' -GCCTTCGCATGTGGTATCAGTAAA- $3^{\prime}$ and $5^{\prime}$-GAAGGGCAGAGTCCGTGGTAATC- $\left.3^{\prime}\right)$, and MMP-12 (5' -TTTCTTCCATATGGCCAAGC- $3^{\prime}$ and $5^{\prime}$ GGTCAAAGACAGCTGCATCA-3'). All human primer sequence were reported previously (Boven et al., 2003), except for AlAR (5'CCCCCTCGCCATCCTCATCA-3' and 5'-GCCCGCTCCACCGCACTC-3') and MMP-12 (5'-GGGGCCCGTATGGAGGAAACA-3' and $5^{\prime}$-CACGGGCAAAAACCACCAAAATG-3'). Semiquantitative analysis 
was performed by monitoring in real-time the increase of fluorescence of the SYBR-green dye (Molecular Probes) on a Bio-Rad (Hercules, CA) i-Cycler. Real-time fluorescence measurements were performed, and a threshold cycle value for each gene of interest was determined, as reported previously (Power et al., 2003). All data were normalized to the glyceraldehyde-3-phosphate dehydrogenase mRNA level and expressed as mRNA relative fold change (RFC).

Cell cultures. Mouse BMDMs were isolated from the pelvic and femoral bone marrow of $\mathrm{A}_{\mathrm{AR}}{ }^{+/+}$or $\mathrm{A} 1 \mathrm{AR}^{-/-}$littermates, as described previously (Riches and Underwood, 1991). The cells were cultured in DMEM containing $2 \mathrm{mM}$ L-glutamine, $100 \mathrm{U} / \mathrm{ml}$ penicillin, $100 \mu \mathrm{g} / \mathrm{ml}$ streptomycin, $10 \%$ heat-inactivated FBS, and 10\% L929 cell-conditioned medium as a source of macrophage colony-stimulating factor-1 in $10 \%$ $\mathrm{CO}^{2}$ for 5-6 d in plastic dishes permitting cellular differentiation, resulting in monolayer cultures that were $>95 \%$ pure macrophages. The medium was replaced with Opti-MEM (Invitrogen) on day 7, and the cells were treated with $100 \mathrm{ng} / \mathrm{ml}$ lipopolysaccharide (LPS), and $50 \mathrm{ng} / \mathrm{ml}$ PMA for $4 \mathrm{hr}$. Cells were harvested and homogenized in TRIzol, whereas supernatants were stored at $-80^{\circ} \mathrm{C}$ for subsequent oligodendrocyte toxicity studies. OLs were isolated from adult Sprague Dawley rat brains and seeded at a density of $5 \times 10^{4}$ cells per well in polyornithine-coated culture chambers (Nunc, Naperville, IL) (Oh et al., 1999). Isolated OLs were differentiated in feeding media (MEM containing 5\% heatinactivated FBS, $0.1 \%$ dextrose, $100 \mathrm{U} / \mathrm{ml}$ penicillin, and $100 \mu \mathrm{g} / \mathrm{ml}$ streptomycin. Culture medium was replaced with AIM V serum-free medium (Invitrogen) and incubated with the supernatant from BMDM culture for $24 \mathrm{hr}$. U937 human monocytoid cells (American Type Culture Collection, Rockville, MD) were initially cultured in RPMI-1640 containing $10 \%$ fetal calf serum, $100 \mathrm{U} / \mathrm{ml}$ penicillin, and $100 \mu \mathrm{g} / \mathrm{ml}$ streptomycin. Culture medium was replaced with AIM V serum-free medium and treated with $50 \mathrm{ng} / \mathrm{ml}$ PMA for $4 \mathrm{hr}$. Total cellular RNA was isolated from the above cells, and A1AR, A2aAR, A3AR, inducible nitric oxide synthase (iNOS), TNF- $\alpha$, IL- $1 \beta$, IL- 10 , IL-4, and MMP- 12 mRNA expressions were quantified using reverse transcription PCR (RT-PCR) analysis as described above.

Human brain tissue samples. Brain tissue (frontal white matter) was collected at autopsy from each experimental group ( $n=7$ controls; $n=$ $7 \mathrm{MS}$ ) and stored at $-80^{\circ} \mathrm{C}$ as described previously (Johnston et al., 2001b). Brain samples from controls were obtained from the Neurovirology Laboratory Brain Bank (Calgary, AB, Canada). Brain tissue from MS patients was obtained from the Multiple Sclerosis Patient Care and Research Clinic (Edmonton, AB, Canada) and was derived from normalappearing white matter. Frontal white matter was homogenized and then lysed in TRIzol, and used in real-time PCR analyses as described above.

Western blot analysis. Protein extracts were prepared from lumbarsacral spinal cord tissue samples with TRIzol (Invitrogen), and concentrations were determined by BCA assay (Pierce, Rockford, IL). Ten micrograms of protein was separated by $10 \%$ SDS-polyacrylamide at $120 \mathrm{~V}$ for $2 \mathrm{hr}$. Proteins were transferred overnight at $4^{\circ} \mathrm{C}$ onto nitrocellulose membranes, followed by blocking with $10 \%$ skimmed milk to prevent nonspecific binding. Membranes were then probed with polyclonal antisera to A1AR (1:1000 dilution; $\alpha$ Diagnostic, San Antonio, TX) or $\beta$-actin (1:100; Chemicon) overnight at $4^{\circ} \mathrm{C}$, followed by washing with TBS-Tween 20. Goat anti-rabbit secondary antibody conjugated to HRP (1:5000 dilution; Chemicon) was used to detect the primary antibody bound to the protein. After several washes, peroxidase activity on the membrane was detected by chemiluminescence (Roche Diagnostics, Laval, Quebec, Canada).

Statistical analysis. Statistical analyses were performed using GraphPad InStat version 3.0 (GraphPad Software, San Diego, CA) for both parametric and nonparametric comparisons. Analysis was performed using the Mann-Whitney $U$ test for neurobehavioral study and the unpaired $t$ test for histopathological changes and real-time RT-PCR analysis. $p$ values of $<0.05$ were considered significant.

\section{Results}

To determine the neurological effects of diminished A1AR expression, we examined the severity of MOG-induced EAE in $\mathrm{AlAR}^{-1-}$ mice compared with $\mathrm{AlAR}^{+/+}$littermate controls. a

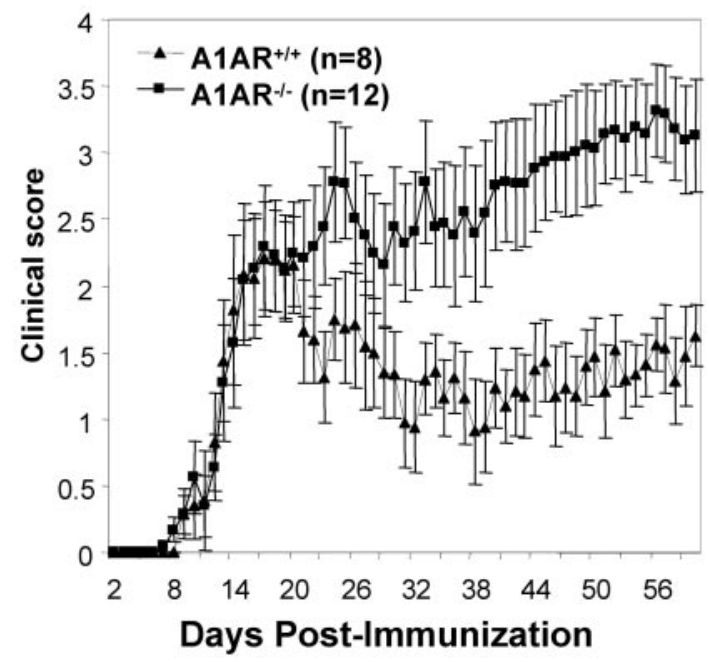

b

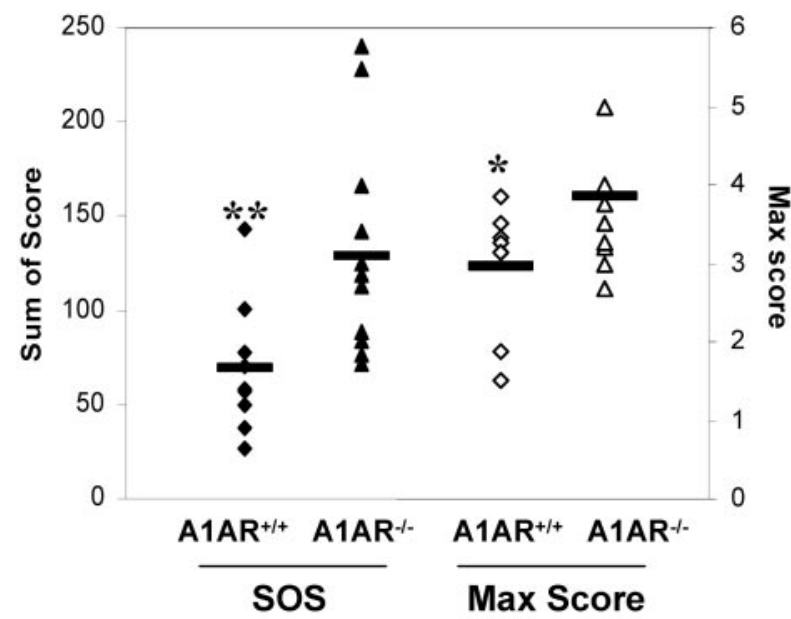

Figure 1. Neurobehavioral outcomes during $\mathrm{EAE}$ in $\mathrm{A}_{1 \mathrm{AR}}{ }^{+/+}$and $\mathrm{A}_{\mathrm{AR}}{ }^{-/-}$animals. $a_{1}$ EAE in A1AR null ( $\mathrm{ATAR}^{-1-}$ ) animals showed a progressive-relapsing phenotype that exhibited more severe clinical scores $\left( \pm\right.$ SEM) than in wild-type littermates $\left(\mathrm{ATAR}^{+1+}\right) \cdot b$, The sum of scores (SOS) per day and maximal disease severity per animal (Max Score) were significantly greater in $\mathrm{A}^{\mathrm{ARR}}{ }^{-1-}$ animals compared with $\mathrm{A1AR}^{+/+}$animals. ${ }^{*} p<0.05 ;{ }^{* *} p<0.01$.

The disease course in this model was a chronic progressiverelapsing phenotype with no difference in the onset and severity of disease between $\mathrm{AlAR}^{-1-}$ and $\mathrm{AlAR}^{+/+}$mice until day 20 after immunization (Fig. 1a). Twenty days after immunization, $\mathrm{AlAR}^{-/-}$animals showed progressive neurological impairment (Fig. 1a), unlike the $\mathrm{A} \mathrm{AR}^{+/+}$mice. In addition, the cumulative neurological disability and the maximal severity of disease was greater for the $\mathrm{A} 1 \mathrm{AR}^{-/-}$animals compared with the wild-type littermates (Fig. 1b), indicating that A1AR expression diminished the severity of EAE after its onset and during disease progression.

MS- and EAE-related neuropathological features include immune activation with demyelination and axonal loss (Lucchinetti et al., 2000). Histopathological analyses of the current experiments revealed that immunoreactivity of the macrophage/microglia marker Iba-1 in lumbar spinal cord was markedly enhanced with cellular hypertrophy and infiltration in both $\mathrm{AlAR}^{-1-}$ and 
a Iba-1

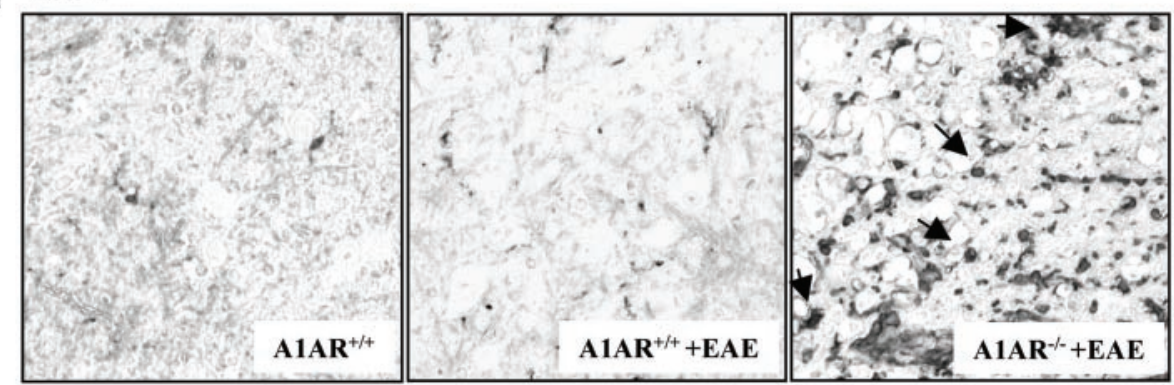

C

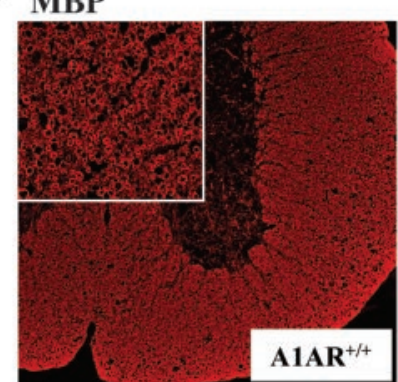

e Silver

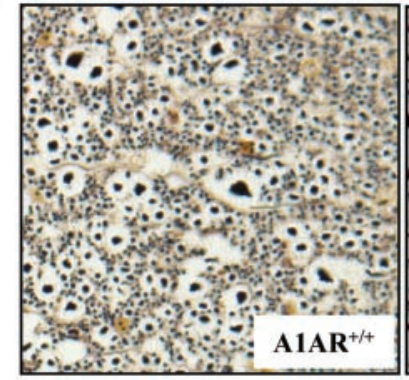

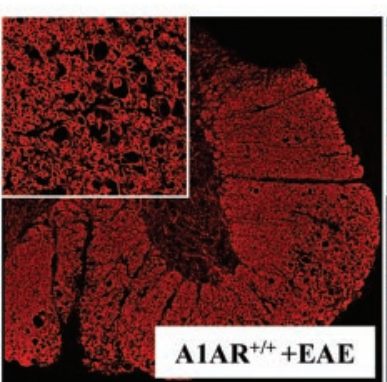
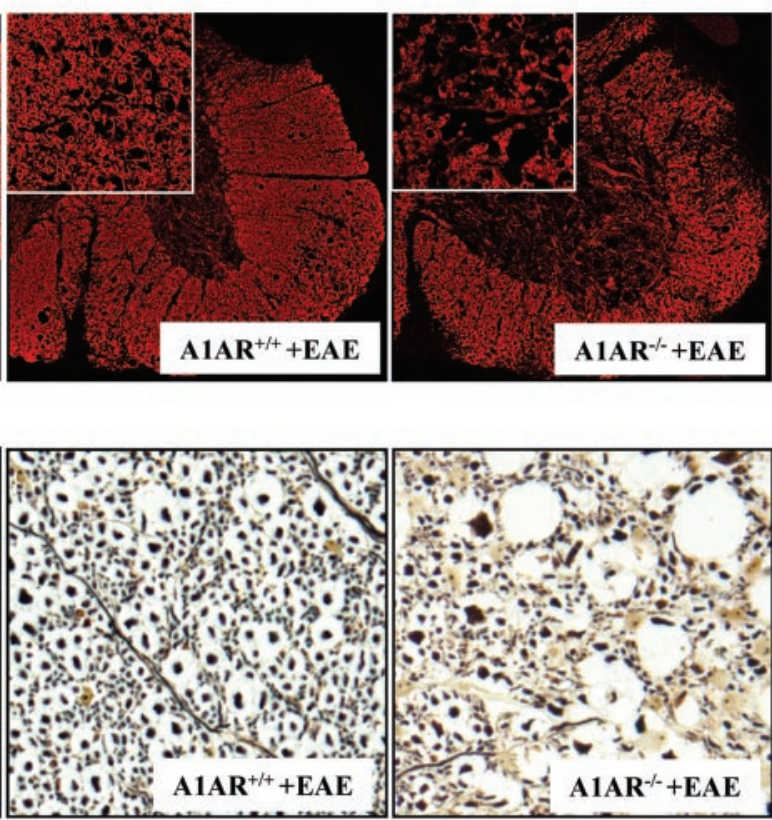

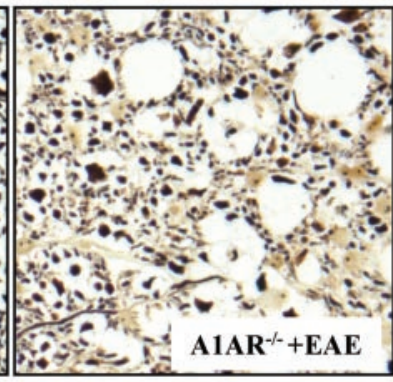

b
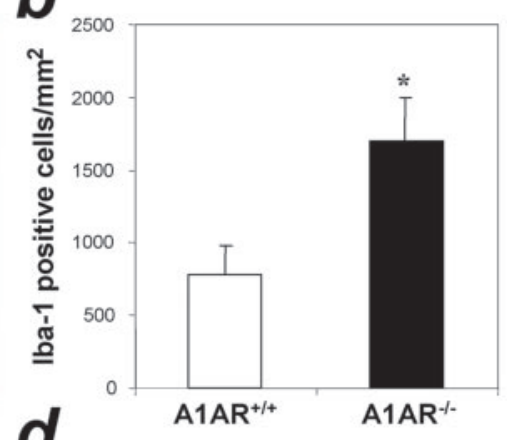

d

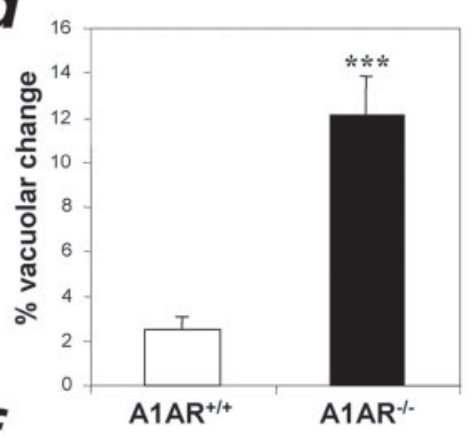

$f$

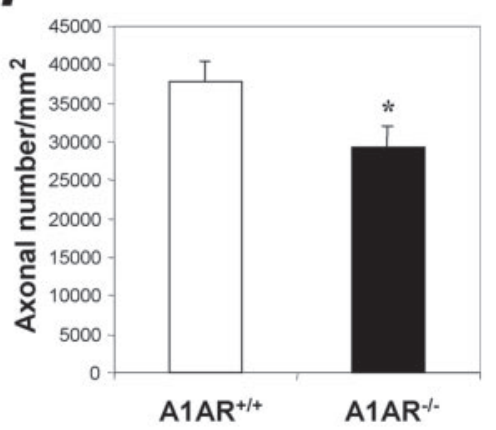

Figure 2. Neuropathological changes in lumbar spinal cord during EAE in $\mathrm{A1AR}^{+/+}$and $A 1 A R^{-1-}$ animals. $a$, lba-1 immunoreactivity was greater with cellular hypertrophy and infiltration (arrows) during EAE in ${\mathrm{A} 1 A R^{-/}}^{-1}$ animals compared with $\mathrm{A} 1 \mathrm{AR}^{+/+}$with EAE and healthy A1AR ${ }^{+/+}$animals (Control) (magnification, 200 $\times$). b, Quantitation of microglial/macrophage immunoreactivity showed a higher mean number of immunopositive cells ( \pm SEM) in $\mathrm{A1AR}^{-/-}$animals with EAE compared with A1AR ${ }^{+/+}$animals with EAE. c, MBP immunoreactivity was reduced in $\mathrm{A}_{\mathrm{AAR}}{ }^{-1-}$ animals with EAE compared with $\mathrm{A}_{1 \mathrm{AR}}{ }^{+/+}$with EAE and $\mathrm{A1AR}^{+/+}$animals without EAE, which was confirmed by the quantitative analysis of mean vacuolar change in myelin ( \pm SEM) (d) (magnification, 100×; insets, 600X). e, Silver-stained axons were fewer in A1AR ${ }^{-/-}$with EAE compared with A1AR ${ }^{+/+}$animals with EAE and control A1AR ${ }^{-/-}$animals (magnification, $1000 \times)$.f, Similarly, mean axon counts $\left( \pm\right.$ SEM) were significantly lower in $\mathrm{A1AR}^{-/-}$animals with EAE compared with $\mathrm{A}^{\mathrm{AAR}}{ }^{+/+}$animals with $\mathrm{EAE}\left(n=4\right.$ per group). ${ }^{*} p<0.05$; ${ }^{* * *} p<0.001$.

$\mathrm{A}_{\mathrm{AAR}}{ }^{+/+}$animals with EAE (Fig. 2a) compared with animals without EAE (Control). Quantitative analysis of Iba-1immunopositive cells after EAE showed greater frequency of detection in $\mathrm{A} 1 \mathrm{AR}^{-/-}$compared with $\mathrm{AlAR}^{+/+}$animals (Fig. 2b). In contrast, no difference in GFAP immunostaining of astrocytes was observed between $\mathrm{AlAR}^{-/-}$and $\mathrm{AlAR}^{+/+}$animals during EAE, although GFAP immunoreactivity was increased in animals after the induction of EAE compared with healthy animals (data not shown). The assessment of myelin indicated that the MBP immunopositive area in the white matter of $\mathrm{AlAR}^{-1-}$ lumbar spinal cord was significantly reduced compared with $\mathrm{A}_{1 \mathrm{AR}}^{+/+}$ animals with and without EAE (Fig. $2 c$ ), which was accompanied by severe vacuolar changes in the white matter of A1AR ${ }^{-1-}$ lumbar spinal cords (Fig. $2 c$ ). The severity of vacuolar changes was quantified by measuring the percentage of the vacuolar area in MBP-stained sections, revealing significantly greater vacuolation in $\mathrm{A} 1 \mathrm{AR}^{-/-}$compared with A1AR ${ }^{+/+}$animals during EAE (Fig. $2 d)$. In conjunction with the myelin changes, silver staining showed that axon detection was decreased in the $\mathrm{AlAR}^{-1-}$ com- pared with the $\mathrm{A} 1 \mathrm{AR}^{+/+}$animals with EAE (Fig. 2e), which was underscored by the quantitative analyses of axon counts (Fig. $2 f$ ). Importantly, neuronal, axonal and glial counts did not differ between $\mathrm{A}_{1 \mathrm{AR}}^{-/-}$and $\mathrm{A} 1 \mathrm{AR}^{+/+}$animals before the induction of EAE (supplemental Figs. 1, 2, available at www.jneurosci.org). Hence, these findings supported the above neurobehavioral observations that absent A1AR expression resulted in worsened neuropathological outcomes during EAE that were defined by greater macrophage/microglial activation together with enhanced demyelination and axonal loss.

The selective expression and release of inflammatory mediators from activated immune cells, such as cytokines, chemokines, and MMPs, contributes to the pathogenesis of both EAE and MS (Navikas and Link, 1996; Sorensen et al., 1999; Vos et al., 2003). Because the A1AR is known to regulate the release and synthesis of immune molecules (Bouma et al., 1994; Boyle et al., 1996; Hasko et al., 1996; Le Moine et al., 1996; Sajjadi et al., 1996; Schwaninger et al., 1997), we investigated the extent to which the absence of A1AR modulates proinflammatory and anti- 
a

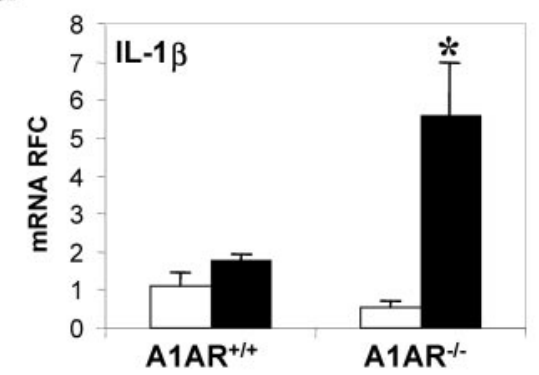

C

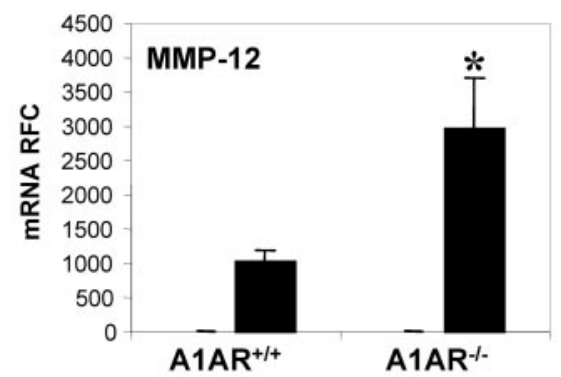

e

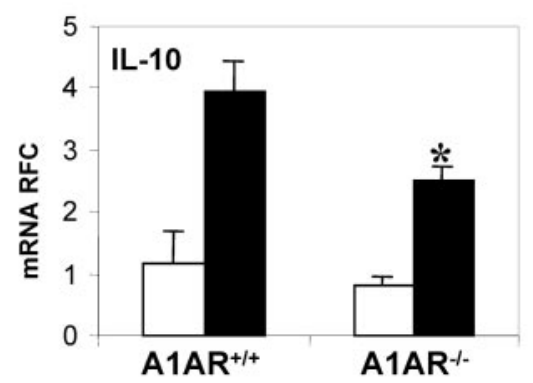

b
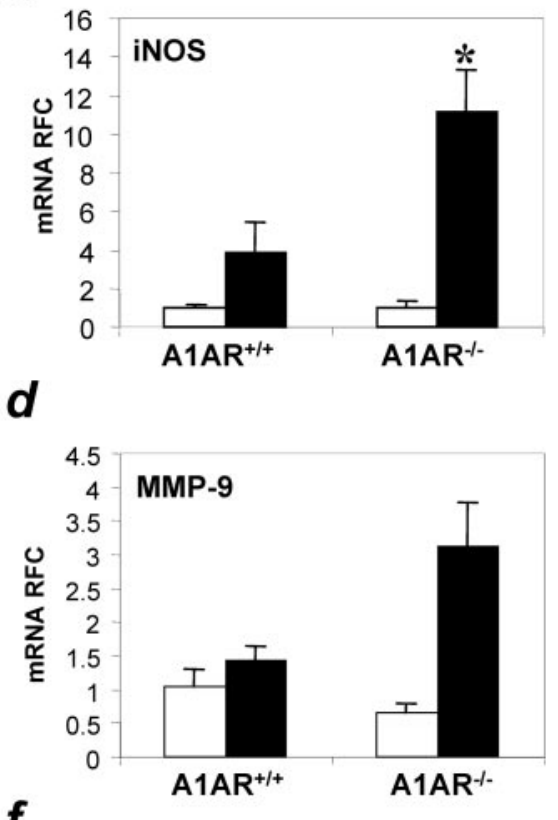

$f$

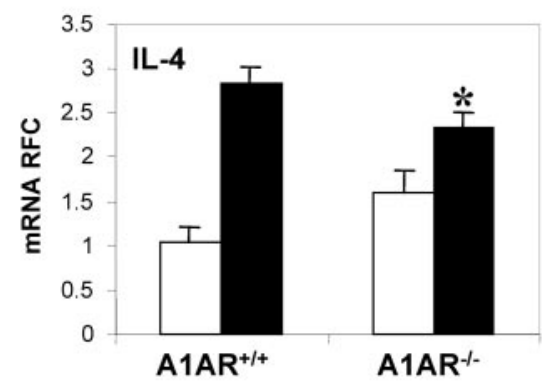

Figure 3. Analysis of mean proinflammatory and anti-inflammatory molecule mRNA RFC ( $\pm \mathrm{SEM})$ in lumbar spinal cord in healthy and EAE-induced in A1AR ${ }^{+/+}$and A1AR ${ }^{-1-}$ animals. RT-PCR showed that mRNA levels for IL-1 $\beta(a)$, iNOS $(b), \operatorname{MMP}-12$ (c), and MMP-9 $(d)$ were significantly higher in A1AR ${ }^{-/-}$animals during EAE compared with A1AR ${ }^{+/+}$animals with EAE when expressed as a fold increase above expression in healthy A1AR ${ }^{+/+}$animals. Conversely, IL-10 $(e)$ and IL-4 ( $f$ ) mRNA levels were lower in the spinal cords of $A 1 A R^{-1-}$ animals during EAE compared with $A 1 A R^{+/+}$animals with EAE. Basal mRNA levels for each gene did not differ between null and wild-type animals ( $n=4$ per group). ${ }^{*} p<0.05$.

inflammatory responses in the CNS during EAE. Although the RFC in mRNA expression of the proinflammatory cytokine IL- $1 \beta$ was induced in $\mathrm{AlAR}^{+/+}$mice after EAE induction, A1 AR ${ }^{-1-}$ EAE mice showed a significant 5.6-fold increase compared with A1AR ${ }^{-1-}$ healthy controls (Fig. 3a). Similarly, iNOS mRNA was induced in $\mathrm{AlAR}^{+/+} \mathrm{EAE}$ mice compared with $\mathrm{AlAR}^{+/+}$healthy controls (Fig. 3b), but $\mathrm{AlAR}^{-1-}$ EAE mice showed significantly greater iNOS expression (Fig. 3b). MMP-12 mRNA expression was also induced in $\mathrm{A}^{\mathrm{AR}}{ }^{+/+}$EAE mice compared with A1AR ${ }^{+/+}$healthy controls (Fig. 3c), but the absence of A1AR significantly augmented MMP-12 expression compared with $\mathrm{AlAR}^{+/+}$EAE mice. MMP-9 mRNA abundance was also increased in $\mathrm{AlAR}^{-1-}$ after EAE compared with healthy $\mathrm{A}_{1 \mathrm{AR}^{-1-}}$ mice (Fig. $3 d$ ), but no differences were observed among wild-type littermates with and without EAE. Conversely, TNF- $\alpha$ mRNA levels were significantly induced in EAE-induced mice, but there was no difference between $\mathrm{AlAR}^{+/+}$and A1AR ${ }^{-1-}$ with EAE (data not shown). Both the antiinflammatory cytokines, IL-10 (Fig. 3e) and IL-4 (Fig. 3f) were significantly reduced in A1AR ${ }^{-1-}$ mice compared with $\mathrm{A}_{\mathrm{AAR}}{ }^{+/+}$mice after EAE. Thus, these studies reflected changes observed in patients with MS but also emphasize the regulatory effects of the A1AR on immune activation in the CNS.

Because macrophage/microglial activation represents a predominant neuropathological finding during progressive MS and was also evident in the present model, we examined the effects of immune activation of macrophages from $\mathrm{AlAR}^{+/+}$ and $\mathrm{AlAR}^{-1-}$ animals after LPS and PMA treatment. Consistent with the present in vivo data, IL-1 $\beta$ and MMP-12 mRNA levels were significantly increased in $\mathrm{AlAR}^{-1-}$ compared with $\mathrm{AlAR}^{+/+}$macrophages after immune stimulation (Fig. 4a), whereas TNF- $\alpha$ expression did not differ between $\mathrm{AlAR}^{-/-}$and $\mathrm{AlAR}^{+/+}$macrophages after activation (data not shown), implying that monocytoid cells were the principal determinants of the proinflammatory gene profile observed in the present in vivo experiments.

Because OLs are susceptible to injury associated with neuroinflammation, their morphology and survival was examined after treatment with supernatants from differentiated, but otherwise untreated, $\mathrm{AlAR}^{+/+}$and $\mathrm{AlAR}^{-1-}$ macrophages. OLs treated with supernatants from $\mathrm{A}_{\mathrm{AAR}}{ }^{-1-}$ macrophages exhibited marked process retraction compared with OLs treated with supernatants from $\mathrm{AlAR}^{+/+}$ macrophages and untreated OLs (Fig. 4b). The quantitation of the number of OLs with processes showed that $\mathrm{AlAR}^{-1-}$. derived supernatants were significantly more cytotoxic than supernatants from differentiated $\mathrm{AlAR}^{+/+}$macrophages and control media (Fig. 4c). Although the OL death percentage was increased in cultures treated with supernatants from both $\mathrm{A}_{\mathrm{ARR}}^{+/+}$and $\mathrm{A} \mathrm{AR}^{-1-}$ macrophages compared with untreated OLs, there was no difference in the OL death rate caused by $\mathrm{AlAR}^{+/+}$and $\mathrm{A}_{\mathrm{AR}}{ }^{-1-}$ supernatants (data not shown). These findings suggest that macrophage-derived soluble factors were toxic to OLs and that the absence of A1AR expression increased the release of cytotoxic factors from macrophages.

To define A1AR expression in the CNS of the healthy wildtype mice, immunofluorescence studies showed that A1AR immunoreactivity in the spinal cord was colocalized principally with the microglia/macrophage marker, anti-Iba-1 (Fig. 5a), with few A1AR-immunopositive neurons (data not shown). However, in $\mathrm{AlAR}^{+/+}$mice during EAE, A1AR mRNA (Fig. $5 b$ ) and protein (Fig. $5 c$ ) expression was reduced in lumbar-sacral spinal cord compared with healthy controls, emphasizing the close coupling of A1AR mRNA and protein expression. Conversely, $\mathrm{A} 2 \mathrm{aAR}$ and A3AR mean RNA levels were increased in lumbarsacral spinal cord during EAE in both $\mathrm{A}_{1} \mathrm{AR}^{+/+}$and $\mathrm{A} 1 \mathrm{AR}^{-1-}$ animals, whereas both the A2aAR and A3AR transcript levels did not differ between $\mathrm{A}_{1} \mathrm{AR}^{+/+}$and $\mathrm{A} 1 \mathrm{AR}^{-/-}$in healthy animals. Although both the A2aAR and A3AR mRNA levels were increased during EAE, only among A1 $\mathrm{AR}^{-1-}$ animal was there a significant increase in the A2aAR levels (Fig. 5b). We also exam- 
ined PMA-stimulated human monocytic cells, U937, which revealed reduced A1AR mRNA and increased MMP-9 expression (Fig. $5 d$ ) compared with untreated controls. Recapitulating the latter finding and previous studies (Mayne et al., 1999; Johnston et al., 2001a), A1AR mRNA expression was also significantly decreased in MS patient brains compared with controls (Fig. 5e). Moreover, mRNA levels of prototypic proinflammatory molecules, including IL-1 $\beta$, MMP-12, and iNOS, were significantly upregulated in MS patients' brains (Fig. 5e), similar to earlier studies (Bagasra et al., 1995; Baranzini et al., 2000). Thus, A1AR expression in the CNS was diminished during both MS and EAE, which was accompanied by enhanced proinflammatory responses in the brains of MS patients compared with controls.

From the above studies, upregulation of the A1AR and/or A1AR activation would be a highly desirable therapeutic strategy; hence, we examined the effects of caffeine and/or ADAC on MOG-induced EAE because chronic caffeine treatment upregulates A1AR expression in the CNS (Shi et al., 1993) and A1AR activation after caffeine treatment might synergistically reduce EAE severity. After the induction of EAE in $\mathrm{AlAR}^{+/+}$mice, A1AR immunoreactivity on macrophage/microglia in spinal cord was reduced (Fig. $6 a$ ), but concurrent treatment of mice with caffeine (2 $\mathrm{mg} / \mathrm{kg}$ ) increased A1AR expression on Iba-1-immunopositive macrophage/microglia, although there was no observable difference in the number of Iba-1-positive cells (Fig. 6a). Analysis of mRNA levels in spinal cord also showed that caffeine treatment significantly reversed EAE-related suppression of A1AR expression, compared with saline-treated animals with EAE (Fig. 6b). Importantly, chronic caffeine treatment also significantly delayed the onset and reduced the severity of neurobehavioral signs in MOGinduced EAE compared with vehicle-treated mice (Fig. $6 c$ ), with concomitant reductions in cumulative neurological disability and maximal severity of disease (Fig. $6 d$ ). To ensure that reversed A1AR expression with caffeine treatment reflected a corresponding enhanced responsiveness to A1AR ligands, caffeine and $\mathrm{ADAC}$ treatments were administered together. Caffeine and ADAC treatment synergistically reduced EAE severity more than caffeine alone. Of interest, low-dose caffeine $(0.2 \mathrm{mg} / \mathrm{kg})$ also increased A1AR mRNA expression and significantly reduced EAE disease severity, albeit to a lesser extent than high-dose caffeine (data not shown). These data indicate that caffeine modulates the severity of EAE by increasing A1AR expression on monocytoid cells, and A1AR activation after caffeine treatment significantly reduced EAE severity.

\section{Discussion}

Here, we demonstrate that the A1AR regulates the severity of EAE-related neurobehavioral and neuropathological outcomes, including demyelination and axonal injury. Although the neuro- pathological parameters suggested marked differences in EAE severity between A1AR wild-type and null animals, the neurobehavioral measures revealed modest changes, likely caused by the limitations of the scoring system. Moreover, microglial/macrophage activation was enhanced in $\mathrm{A} \mathrm{AR}^{-1-}$ animals and A1AR deficiency increased proinflammatory responses, whereas the anti-inflammatory genes were suppressed together with increased oligodendrocyte cytotoxicity compared with littermate controls. Chronic caffeine treatment increased the A1AR expression in macrophage/microglia during EAE, with an ensuing attenuation of disease, and concomitant ADAC treatment from the onset of EAE further enhanced the reduction of disease severity, raising the possibility of treating inflammatory demyelination by increasing A1AR activity and expression.

Earlier studies from our group reported that A1AR mRNA and protein levels were reduced in blood and brain monocytoid cells from patients with MS with associated dysregulation of cytokine expression (Mayne et al., 1999; Johnston et al., 2001a). Similarly, the present study shows that the A1AR is downregulated on microglia during MOG-EAE. These findings suggest that transcriptional control or transcript degradation of A1AR gene was perturbed during CNS inflammation, which is in contrast with findings in asthma, in which antagonism of the A1AR improves outcomes (Fozard and McCarthy, 2002). The expression 
a
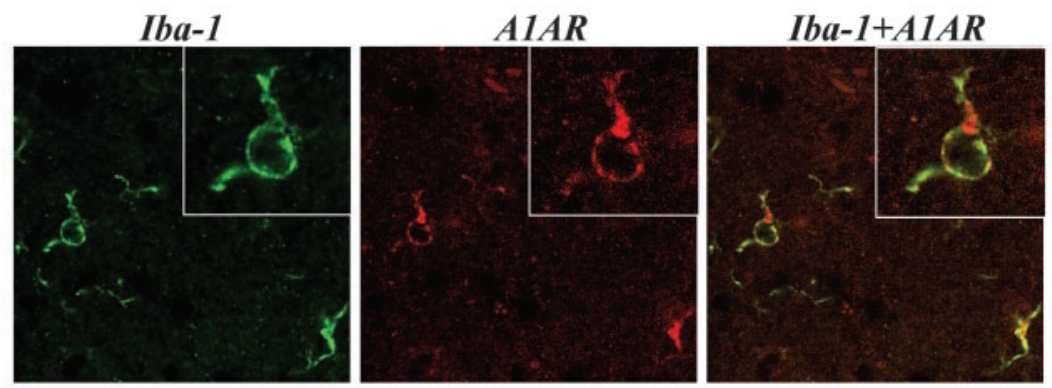

b

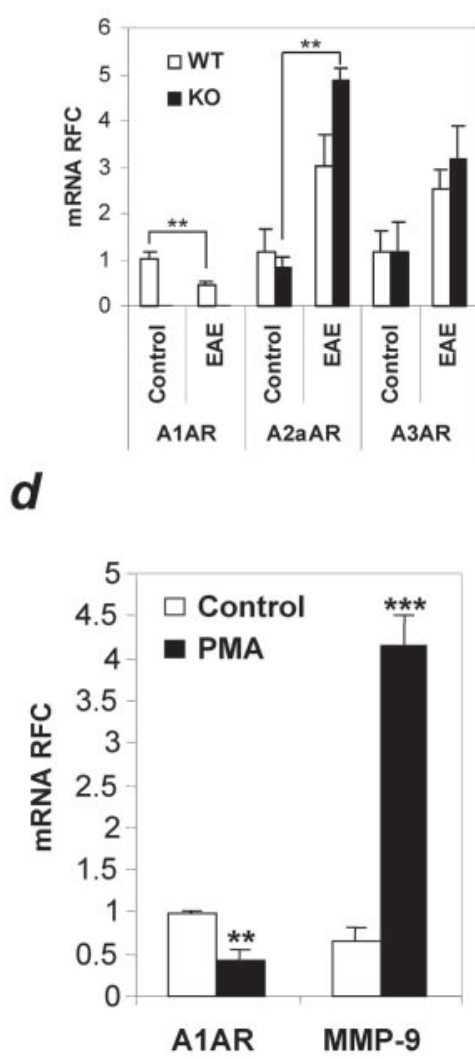

C

e
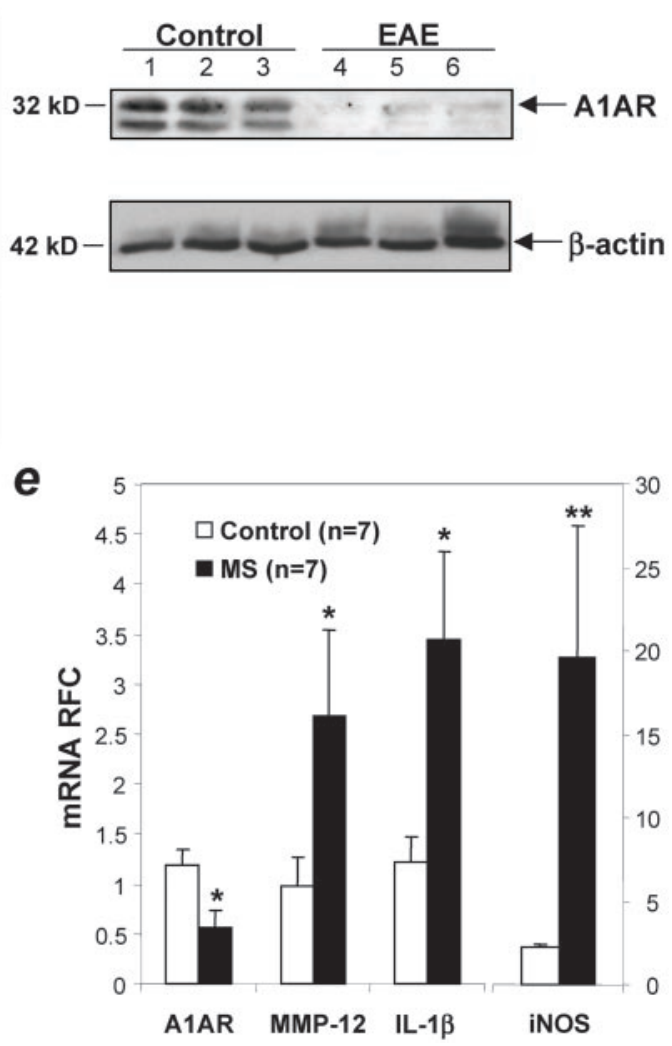

Figure 5. A1AR expression is reduced in EAE and MS. $a$, Double-label immunofluorescence shows the microglial marker Iba-1 colocalizing with the A1AR (inset) in the normal mouse spinal cord. $b$, Analysis of mean mRNA levels of adenosine receptors ( \pm SEM) in ATAR ${ }^{+/+}$and A1AR ${ }^{-/-}$animals by real-time RT-PCR in both healthy (Control) and EAE (EAE) animals revealed that A1AR mRNA levels were undetectable in $A 1 A R^{-1-}$ animals and that A1AR levels were suppressed in $A 1 A R^{+/+}$animals during EAE. However, both A2aAR and A3AR mRNA levels were augmented during EAE in $A 1 A R^{+/+}$and $A 1 A R^{-1-}$ animals, whereas the mRNA levels of both receptors did not differ between $A 1 A R^{+/+}$and $A 1 A R^{-1-}$ in healthy animals. $c$, Western blotting confirmed lower A1AR protein levels in animals with EAE compared with healthy animals (Control). d, PMA treatment of human U937 monocytoid cells showed reduced A1AR and increased MMP-9 mean mRNA levels ( \pm SEM) compared with unstimulated cells (Control). e, Brain tissue from MS patients exhibited reduced mean A1AR levels ( \pm SEM) compared with control patients, butmean MMP-12,IL-1 $\beta$, and iNOS mRNA levels ( \pm SEM) were increased in MS patients (magnification, $400 \times$ ). ${ }^{*} p<0.05$; ${ }^{* *} p<0.01$.

of A1AR gene is controlled by two separate promoters that regulate the expression of the $\mathrm{A} 1 \alpha$ and $\mathrm{A} 1 \beta$ transcripts, respectively, in different tissues (Ren and Stiles, 1994, 1995). Indeed, in the present studies we observed two A1AR immunoreactive bands on Western blotting, which may reflect splice variants, although both were reduced in EAE-affected animals. However, our previous studies showed that the A1 $\beta$ transcript was preferentially reduced in MS brains, which may reflect a lack in the putative transcriptional factor, AGG binding protein, that drives A1AR expression (Olah and Stiles, 1995). Of interest, glucocorticoids, frequently used in the treatment of MS, also enhance A1AR ex- pression through their actions on binding sites in the A1AR gene promoter (Svenningsson and Fredholm, 1997; Ren and Stiles, 1999). Given that the A1AR regulates innate inflammatory responses in macrophages and neutrophils (Linden, 2001), diminished A1AR expression would be expected to exacerbate CNS inflammatory diseases, although the precise effects were unclear until the present study.

Adenosine-mediated anti-inflammatory effects have been studied chiefly in macrophage-like cells, with inhibitory effects on cytokine, chemokine, and MMP release (Le Moine et al., 1996; De Stefano et al., 1998). Macrophage/microglial infiltration and activation are key features of EAE in the present AlAR null mouse model. This finding is emphasized by the marked increase in vitro and in vivo of MMP-12 (macrophage metalloelastase) mRNA in A1AR null mice, which is selectively expressed in monocytoid cells. Of interest, this latter observation is supported by our finding of increased MMP-12 mRNA in the brains of MS patients and a study showing MMP-12 protein in macrophages of demyelinating lesions (Vos et al., 2003). Although the MMP-12 substrate in demyelination remains uncertain, a neuropathogenic role for MMP-12 is plausible, given very recent studies from our group showing that MMP-2 is neurotoxic through a mechanism by which a chemokine is cleaved, resulting in a highly neurotoxic molecule (Zhang et al., 2003). The precise substrate for MMP-12 in the present context is currently under investigation.

Because lymphocyte infiltration and activation are important early determinants of MS and EAE onset (Bar-Or et al., 1999), but they minimally express the A1AR, it was not surprising to find that the severity of EAE at the onset of disease in the present model did not differ between A1AR null and wild-type animals. However, the subsequent induction of proinflammatory and inhibition of antiinflammatory molecules during EAE in the A1AR null mouse also reflects the inflammatory profile of MS, which likely contributes to demyelination and axonal injury, both observed herein. Likewise, supernatants from differentiated A1AR null macrophages were cytotoxic to mouse oligodendrocytes, which implies a toxic mechanism causing demyelination in the present model. Although the soluble cytotoxic factor(s) remains unknown, studies with glutamate receptor antagonists failed to inhibit oligodendrocyte injury (data not shown). The present A1AR null mouse model does not exhibit a neurobehavioral or neuropathological phenotype (supplemental Figs. 1, 2, available at www.jneurosci.org) during health (Sun et al., 2001), indicating the activation or differentiation of microglia is required for a disease phenotype in this model. Conversely, 
another A1AR null mouse model showed an anxiety/aggression phenotype, perhaps caused by a different knock-out strategy or background animal strain (Gimenez-Llort et al., 2002).

The neuroprotective properties of caffeine are attributable to several mechanisms, including its phosphodiesterase inhibition (Dall'lgna et al., 2003), but antagonism of adenosine receptors is also a recognized caffeine-related effect (Chou and Vickroy, 2003). Chronic caffeine treatment upregulates A1AR expression through chronic receptor antagonism (Shi et al., 1993) with improved outcomes after cerebral ischemia (Bona et al., 1995), possibly caused by the activation of downstream signaling molecules, including cAMP, protein kinase C, phosphatidylinositol-3 kinase, and MAP kinases (Linden, 2001). Continuous delivery of caffeine markedly reduced the severity of EAE, which was accompanied by an increase in A1AR expression on spinal cord microglia in the present studies. In vitro caffeine treatment of human monocytoid cells also increased A1AR expression and reduced proinflammatory cytokine production (data not shown). The present observations of macrophage-dependent effects influencing the outcome of EAE is compatible with earlier studies showing that the monocytoid cells are an essential component of EAE-related disease (Bauer et al., 1995). Of interest, a recent clinical trial of a mixture of caffeine and histamine in patients with MS showed significant improvement in patients' symptoms (Gillson et al., 2002). Other A1AR-inducing drugs, such as glucocorticoids, are a standard treatment for acute MS relapses, but their side effects preclude longterm use. Although the A1AR-specific agonist ADAC nonsignificantly delayed the onset of EAE (data not shown), a combination of caffeine with ADAC synergistically diminished EAE severity, underscoring the impact of increasing A1AR expression and thereby making more receptors available to A1AR agonists. The high affinity of ADAC for the A1AR (Jacobson et al., 1987) likely displaces the chronic antagonistic effects of caffeine (Jacobson et al., 1996), resulting in accentuated downstream A1ARmediated actions.

Thus, our findings point to a mechanism by which the A1AR is involved in demyelination and axonal loss in EAE and MS pathogenesis. Initially, A1AR expression is downregulated by immune stimulation and perhaps genetic susceptibility. Reduced A1AR expression in microglia/macrophages leads to enhanced proinflammatory responses and the release of cytotoxic factors. Cytotoxins induce oligodendrocyte degeneration, resulting in demyelination and associated axonal loss. However, A1AR activation after its upregulation by caffeine enhances related downstream signaling pathways, suppressing proinflammatory and augmenting anti-inflammatory responses, which diminish oligodendrocyte cytotoxicity together with maintaining the integrity of the myelin sheath and associated axon. In toto, these observa-
Iba-1

AIAR

Iba-1+A1AR

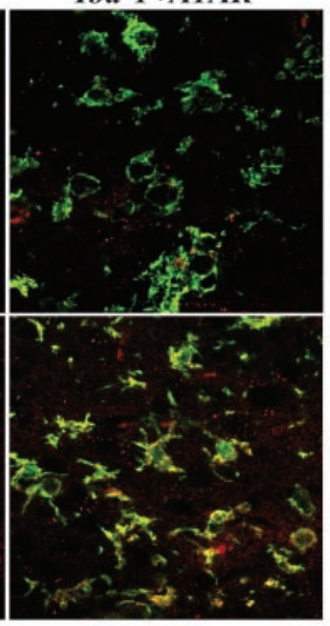

d
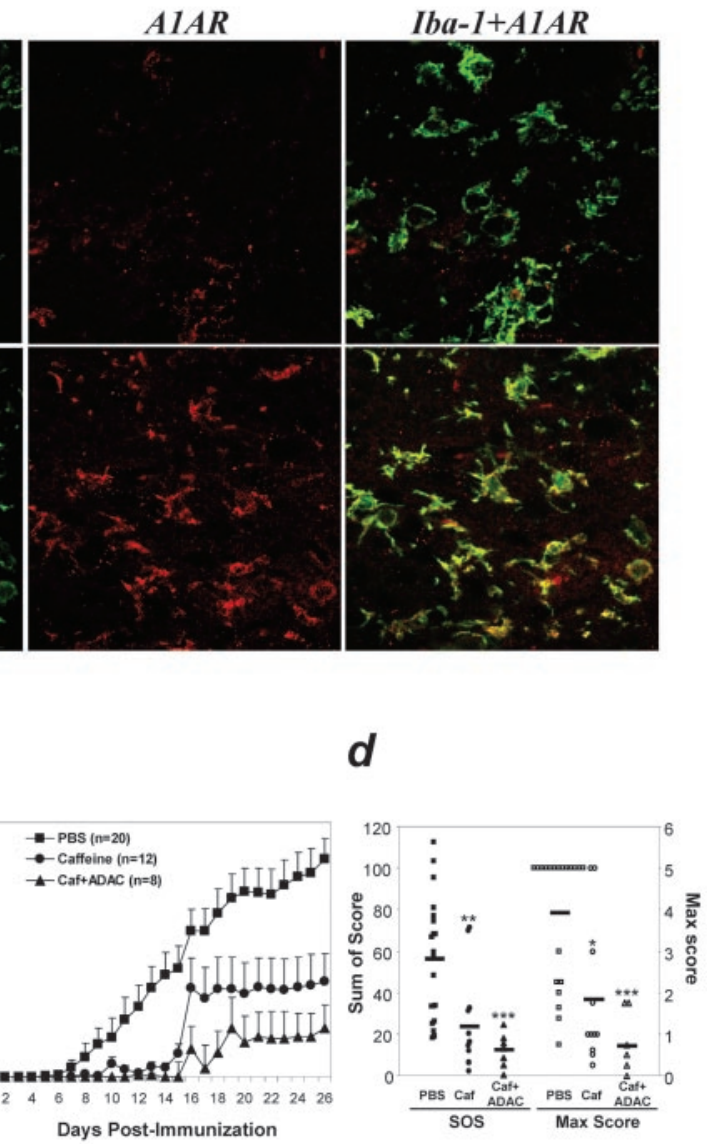

C

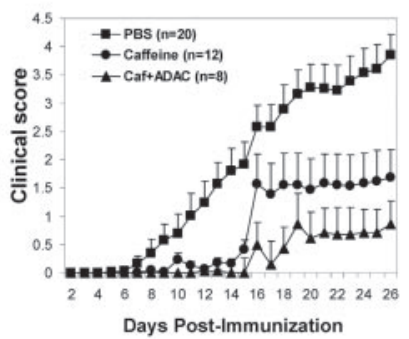

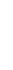

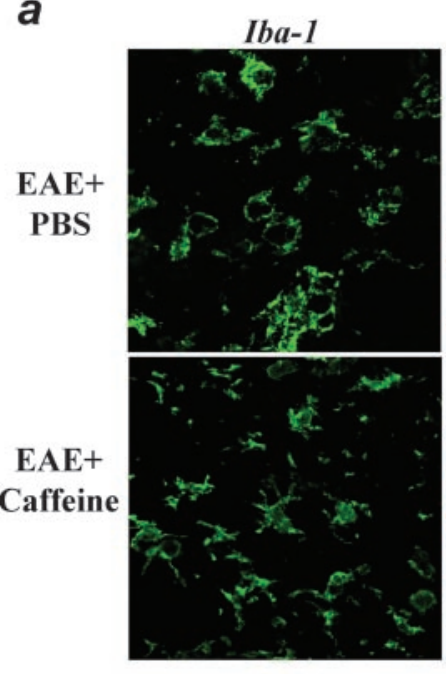

Figure 6. A1AR expression is increased by caffeine during EAE. $a$, Chronic caffeine treatment of EAE-induced A1AR ${ }^{+/+}$ animals showed that A1AR expression was increased on Iba-1-immunopositive microglia/macrophages compared with untreated animals after EAE induction. $b$, Mean A1AR mRNA expression ( \pm SEM) was increased in A1AR ${ }^{+/+}$animals with EAE after significantly reduced and delayed, respectively (mean clinical score \pm SEM), in $A 1 A R^{+/+}$animals receiving chronic caffeine treatment, which may be synergistically accentuated by concomitant treatment with ADAC. $d$, The sum of scores per day and maximal disease severity per animal were significantly diminished in caffeine-treated animals, again, markedly enhanced by concomitant treatment with $\mathrm{ADAC}^{*} p<0.05{ }^{* * *} p<0.001$.

tions raise the possibility of using A1AR modulators and agonists in the treatment of neuroinflammatory diseases.

\section{References}

Bagasra O, Michaels FH, Zheng YM, Bobroski LE, Spitsin SV, Fu ZF, Tawadros R, Koprowski H (1995) Activation of the inducible form of nitric oxide synthase in the brains of patients with multiple sclerosis. Proc Natl Acad Sci USA 92:12041-12045.

Bansal R, Warrington AE, Gard AL, Ranscht B, Pfeiffer SE (1989) Multiple and novel specificities of monoclonal antibodies O1, O4, and R-mAb used in the analysis of oligodendrocyte development. J Neurosci Res 24:548-557.

Baranzini SE, Elfstrom C, Chang SY, Butunoi C, Murray R, Higuchi R, Oksenberg JR (2000) Transcriptional analysis of multiple sclerosis brain lesions reveals a complex pattern of cytokine expression. J Immunol 165:6576-6582.

Bar-Or A, Oliveira EM, Anderson DE, Hafler DA (1999) Molecular pathogenesis of multiple sclerosis. J Neuroimmunol 100:252-259.

Bauer J, Huitinga I, Zhao W, Lassmann H, Hickey WF, Dijkstra CD (1995) The role of macrophages, perivascular cells, and microglial cells in the pathogenesis of experimental autoimmune encephalomyelitis. Glia 15:437-446.

Bona E, Aden U, Fredholm BB, Hagberg H (1995) The effect of long term caffeine treatment on hypoxic-ischemic brain damage in the neonate. Pediatr Res 38:312-318.

Bouma MG, Stad RK, van den Wildenberg FA, Buurman WA (1994) Dif- 
ferential regulatory effects of adenosine on cytokine release by activated human monocytes. J Immunol 153:4159-4168.

Boven LA, Vergnolle N, Henry SD, Silva C, Imai Y, Holden J, Warren K, Hollenberg MD, Power C (2003) Up-regulation of proteinase-activated receptor 1 expression in astrocytes during HIV encephalitis. J Immunol 170:2638-2646

Boyle DL, Sajjadi FG, Firestein GS (1996) Inhibition of synoviocyte collagenase gene expression by adenosine receptor stimulation. Arthritis Rheum 39:923-930.

Brundula V, Rewcastle NB, Metz LM, Bernard CC, Yong VW (2002) Targeting leukocyte MMPs and transmigration: minocycline as a potential therapy for multiple sclerosis. Brain 125:1297-1308.

Chandler S, Miller KM, Clements JM, Lury J, Corkill D, Anthony DC, Adams SE, Gearing AJ (1997) Matrix metalloproteinases, tumor necrosis factor and multiple sclerosis: an overview. J Neuroimmunol 72:155-161.

Chou CC, Vickroy TW (2003) Antagonism of adenosine receptors by caffeine and caffeine metabolites in equine forebrain tissues. Am J Vet Res 64:216-224.

Cronstein BN (1994) Adenosine, an endogenous anti-inflammatory agent. J Appl Physiol 76:5-13.

Dall'lgna OP, Porciuncula LO, Souza DO, Cunha RA, Lara DR (2003) Neuroprotection by caffeine and adenosine $\mathrm{A} 2 \mathrm{~A}$ receptor blockade of betaamyloid neurotoxicity. Br J Pharmacol 138:1207-1209.

De Stefano N, Matthews PM, Fu L, Narayanan S, Stanley J, Francis GS, Antel JP, Arnold DL (1998) Axonal damage correlates with disability in patients with relapsing-remitting multiple sclerosis: results of a longitudinal magnetic resonance spectroscopy study. Brain 121:1469-1477.

Fozard JR, McCarthy C (2002) Adenosine receptor ligands as potential therapeutics in asthma. Curr Opin Investig Drugs 3:69-77.

Gillson G, Richard TL, Smith RB, Wright JV (2002) A double-blind pilot study of the effect of Prokarin on fatigue in multiple sclerosis. Mult Scler 8:30-35.

Gimenez-Llort L, Fernandez-Teruel A, Escorihuela RM, Fredholm BB, Tobena A, Pekny M, Johansson B (2002) Mice lacking the adenosine A1 receptor are anxious and aggressive, but are normal learners with reduced muscle strength and survival rate. Eur J Neurosci 16:547-550.

Hasko G, Szabo C, Nemeth ZH, Kvetan V, Pastores SM, Vizi ES (1996) Adenosine receptor agonists differentially regulate IL-10, TNF-alpha, and nitric oxide production in RAW 264.7 macrophages and in endotoxemic mice. J Immunol 157:4634-4640.

Imai Y, Ibata I, Ito D, Ohsawa K, Kohsaka S (1996) A novel gene ibal in the major histocompatibility complex class III region encoding an EF hand protein expressed in a monocytic lineage. Biochem Biophys Res Commun 224:855-862.

Jacobson KA, Zimmet J, Schulick R, Barone S, Daly JW, Kirk KL (1987) Adenosine analogs with covalently attached lipids have enhanced potency at A1-adenosine receptors. FEBS Lett 225:97-102.

Jacobson KA, von Lubitz DK, Daly JW, Fredholm BB (1996) Adenosine receptor ligands: differences with acute versus chronic treatment. Trends Pharmacol Sci 17:108-113.

Johnston JB, Silva C, Gonzalez G, Holden J, Warren KG, Metz LM, Power C (2001a) Diminished adenosine A1 receptor expression on macrophages in brain and blood of patients with multiple sclerosis. Ann Neurol 49:650-658.

Johnston JB, Silva C, Holden J, Warren KG, Clark AW, Power C (2001b) Monocyte activation and differentiation augment human endogenous retrovirus expression: implications for inflammatory brain diseases. Ann Neurol 50:434-442.

Lassmann H, Bruck W, Lucchinetti C (2001) Heterogeneity of multiple sclerosis pathogenesis: implications for diagnosis and therapy. Trends Mol Med 7:115-121.

Le Moine O, Stordeur P, Schandene L, Marchant A, de Groote D, Goldman M, Deviere J (1996) Adenosine enhances IL-10 secretion by human monocytes. J Immunol 156:4408-4414.

Linden J (2001) Molecular approach to adenosine receptors: receptormediated mechanisms of tissue protection. Annu Rev Pharmacol Toxicol 41:775-787.

Linker RA, Maurer M, Gaupp S, Martini R, Holtmann B, Giess R, Rieckmann $\mathrm{P}$, Lassmann H, Toyka KV, Sendtner M, Gold R (2002) CNTF is a major protective factor in demyelinating CNS disease: a neurotrophic cytokine as modulator in neuroinflammation. Nat Med 8:620-624.

Liu J, Marino MW, Wong G, Grail D, Dunn A, Bettadapura J, Slavin AJ, Old L, Bernard CC (1998) TNF is a potent anti-inflammatory cytokine in autoimmune-mediated demyelination. Nat Med 4:78-83.
Lucchinetti C, Bruck W, Parisi J, Scheithauer B, Rodriguez M, Lassmann H (2000) Heterogeneity of multiple sclerosis lesions: implications for the pathogenesis of demyelination. Ann Neurol 47:707-717.

Mayne M, Shepel PN, Jiang Y, Geiger JD, Power C (1999) Dysregulation of adenosine A1 receptor-mediated cytokine expression in peripheral blood mononuclear cells from multiple sclerosis patients. Ann Neurol 45:633-639.

Miller SD, Shevach EM (1998) Immunoregulation of experimental autoimmune encephalomyelitis: editorial overview. Res Immunol 149:753-759.

Navikas V, Link H (1996) Cytokines and the pathogenesis of multiple sclerosis. J Neurosci Res 45:322-333.

Neuhaus O, Archelos JJ, Hartung HP (2003) Immunomodulation in multiple sclerosis: from immunosuppression to neuroprotection. Trends Pharmacol Sci 24:131-138.

Oh LY, Larsen PH, Krekoski CA, Edwards DR, Donovan F, Werb Z, Yong VW (1999) Matrix metalloproteinase-9/gelatinase B is required for process outgrowth by oligodendrocytes. J Neurosci 19:8464-8475.

Olah ME, Stiles GL (1995) Adenosine receptor subtypes: characterization and therapeutic regulation. Annu Rev Pharmacol Toxicol 35:581-606.

Overbergh L, Valckx D, Waer M, Mathieu C (1999) Quantification of murine cytokine mRNAs using real time quantitative reverse transcriptase PCR. Cytokine 11:305-312.

Power C, Henry S, Del Bigio MR, Larsen PH, Corbett D, Imai Y, Yong VW, Peeling J (2003) Intracerebral hemorrhage induces macrophage activation and matrix metalloproteinases. Ann Neurol 53:731-741.

Ren H, Stiles GL (1994) Posttranscriptional mRNA processing as a mechanism for regulation of human Al adenosine receptor expression. Proc Natl Acad Sci USA 91:4864-4866.

Ren H, Stiles GL (1995) Separate promoters in the human Al adenosine receptor gene direct the synthesis of distinct messenger RNAs that regulate receptor abundance. Mol Pharmacol 48:975-980.

Ren H, Stiles GL (1999) Dexamethasone stimulates human A1 adenosine receptor $(\mathrm{A} 1 \mathrm{AR})$ gene expression through multiple regulatory sites in promoter B. Mol Pharmacol 55:309-316.

Ribeiro JA, Sebastiao AM, de Mendonca A (2002) Adenosine receptors in the nervous system: pathophysiological implications. Prog Neurobiol 68:377-392.

Riches DW, Underwood GA (1991) Expression of interferon-beta during the triggering phase of macrophage cytocidal activation: evidence for an autocrine/paracrine role in the regulation of this state. J Biol Chem 266:24785-24792.

Sajjadi FG, Takabayashi K, Foster AC, Domingo RC, Firestein GS (1996) Inhibition of TNF-alpha expression by adenosine: role of A3 adenosine receptors. J Immunol 156:3435-3442.

Schwaninger M, Neher M, Viegas E, Schneider A, Spranger M (1997) Stimulation of interleukin-6 secretion and gene transcription in primary astrocytes by adenosine. J Neurochem 69:1145-1150.

Shi D, Nikodijevic O, Jacobson KA, Daly JW (1993) Chronic caffeine alters the density of adenosine, adrenergic, cholinergic, GABA, and serotonin receptors and calcium channels in mouse brain. Cell Mol Neurobiol 13:247-261.

Sommer I, Schachner M (1981) Monoclonal antibodies (O1 to O4) to oligodendrocyte cell surfaces: an immunocytological study in the central nervous system. Dev Biol 83:311-327.

Sorensen TL, Tani M, Jensen J, Pierce V, Lucchinetti C, Folcik VA, Qin S, Rottman J, Sellebjerg F, Strieter RM, Frederiksen JL, Ransohoff RM (1999) Expression of specific chemokines and chemokine receptors in the central nervous system of multiple sclerosis patients. J Clin Invest 103:807-815.

Sun D, Samuelson LC, Yang T, Huang Y, Paliege A, Saunders T, Briggs J, Schnermann J (2001) Mediation of tubuloglomerular feedback by adenosine: evidence from mice lacking adenosine 1 receptors. Proc Natl Acad Sci USA 98:9983-9988.

Svenningsson P, Fredholm BB (1997) Glucocorticoids regulate the expression of adenosine $\mathrm{A} 1$ but not $\mathrm{A}(2 \mathrm{~A})$ receptors in rat brain. J Pharmacol Exp Ther 280:1094-1101.

Vos CM, van Haastert ES, de Groot CJ, van der Valk P, de Vries HE (2003) Matrix metalloproteinase- 12 is expressed in phagocytotic macrophages in active multiple sclerosis lesions. J Neuroimmunol 138:106-114.

Yong VW, Krekoski CA, Forsyth PA, Bell R, Edwards DR (1998) Matrix metalloproteinases and diseases of the CNS. Trends Neurosci 21:75-80.

Zhang K, McQuibban GA, Silva C, Butler GS, Johnston JB, Holden J, ClarkLewis I, Overall CM, Power C (2003) HIV-induced metalloproteinase processing of the chemokine stromal cell derived factor- 1 causes neurodegeneration. Nat Neurosci 6:1064-1071. 